\title{
Greater muscle strength is associated with reduced autonomic reactivity
}

\author{
Maior força muscullar está associada à reatividade autonômica reduzida \\ Una mayor fuerza muscular está asociada con reactividad autonómica reducida
}

Received: 04/29/2021 | Reviewed: 05/06/2021 |Accept: 05/10/2021 | Published: 05/26/2021

\author{
José Morais Souto Filho \\ ORCID: https://orcid.org/0000-0001-8874-1708 \\ Catholic University of Brasilia, Brazil \\ E-mail: morais.edpe@gmail.com \\ Caio Victor de Souza \\ ORCID: https://orcid.org/0000-0002-0499-2372 \\ University of Miami, United States of America \\ E-mail: cvsousa89@gmail.com \\ Thiago dos Santos Rosa \\ ORCID: https://orcid.org/0000-0003-0418-0945 \\ Catholic University of Brasilia, Brazil \\ E-mail: thiagoacsdkp@yahoo.com.br \\ Herbert Gustavo Simões \\ ORCID: https://orcid.org/0000-0002-2378-4026 \\ Catholic University of Brasilia, Brazil \\ E-mail: hgsimoes@gmail.com
}

\begin{abstract}
We aimed to investigate the autonomic responses to cold pressor test (CPT) in individual with different levels of muscle strength. 57 male subjects participated in the study. Volunteers were divided in tertiles according to their level of relative handgrip strength as Low (LS), Medium (MS) and High (HS). For the CPT the volunteers remained seated in resting for 15 minutes and inserted the right hand in cold water for two minutes. Blood pressure (BP) measurements were taken at rest, during CPT and during recovery. HRV was continuously recorded during the entire protocol. All three groups had similar BP variation, with the values of systolic blood pressure (SBP) increasing during CPT and diminishing during recovery until the third minute. At the first CPT minute LS group showed a substantial increase in low-frequency (LF) activity and a diminished high frequency (HF). LS also presented higher and lower values of LF and HF, respectively, than MS group at the first CPT minute. HS showed an increased vagal activity during recovery. In conclusion, individuals from LS presented similar BP responses to CPT than MS and HS groups but with higher sympathetic activation. HS individuals presented an elevated vagal activity during recovery.
\end{abstract}

Keywords: Heart rate; Heart rate variability; Handgrip; Cardiovascular; Stress; Physical fitness.

\section{Resumo}

Nosso objetivo foi investigar as respostas autonômicas ao teste pressor a frio (CPT) em indivíduos com diferentes níveis de força muscular. 57 sujeitos do sexo masculino participaram do estudo. Os voluntários foram divididos em tercis de acordo com seu nível de força de preensão manual relativa como Baixo (LS), Médio (MS) e Alto (HS). Para o CPT os voluntários permaneceram sentados em repouso por 15 minutos e inseriram a mão direita em água fria por dois minutos. As medidas da pressão arterial (PA) foram realizadas em repouso, durante o TCP e durante a recuperação. A VFC foi registrada continuamente durante todo o protocolo. Os três grupos apresentaram variação semelhante da PA, com os valores da pressão arterial sistólica (PAS) aumentando durante o TCP e diminuindo na recuperação até o terceiro minuto. No primeiro minuto do CPT, o grupo LS mostrou um aumento substancial na atividade de baixa frequência (LF) e uma diminuição na alta frequência (HF). LS também apresentou valores maiores e menores de $\mathrm{BF}$ e AF, respectivamente, do que o grupo MS no primeiro minuto do TCP. HS mostrou um aumento da atividade vagal durante a recuperação. Em conclusão, os indivíduos de LS apresentaram respostas de PA semelhantes ao CPT do que os grupos MS e HS, mas com maior ativação simpática. Indivíduos com HS apresentaram atividade vagal elevada durante a recuperação.

Palavras-chave: Frequência cardíaca; Variabilidade da frequência cardíaca; Força; Atividade física.

\section{Resumen}

Nuestro objetivo fue investigar las respuestas autonómicas a la prueba de presión en frío (CPT) en individuos con diferentes niveles de fuerza muscular. 57 sujetos masculinos participaron en el estudio. Los voluntarios se dividieron en terciles de acuerdo con su nivel relativo de fuerza de agarre, como Bajo (LS), Medio (MS) y Alto (HS). Para el CPT, los voluntarios se sentaron en reposo durante 15 minutos e insertaron su mano derecha en agua fría durante dos minutos. Las mediciones de la presión arterial (PA) se realizaron en reposo, durante la PCT y durante la recuperación. 
La VFC se registró de forma continua a lo largo del protocolo. Los tres grupos mostraron una variación similar en la PA, con los valores de la presión arterial sistólica (PAS) aumentando durante la PCT y disminuyendo en la recuperación hasta el tercer minuto. En el primer minuto de CPT, el grupo LS mostró un aumento sustancial en la actividad de baja frecuencia (LF) y una disminución en la alta frecuencia (HF). LS también mostró valores más altos y más bajos para $\mathrm{BF}$ y AF, respectivamente, que el grupo de MS en el primer minuto de TCP. HS mostró un aumento en la actividad vagal durante la recuperación. En conclusión, los individuos LS mostraron respuestas de PA similares a CPT que los grupos MS y HS, pero con mayor activación simpática. Los individuos con HS mostraron una alta actividad vagal durante la recuperación.

Keywords: Frecuencia cardíaca; Variabilidad de la frecuencia cardíaca, Fuerza; Actividad física.

\section{Introduction}

Modern society has been exposed to an increasing frequency of acute stress situations. Thus, both the autonomic, metabolic, cardiovascular and even inflammatory responses can become hyper-reactive to acute situations, and thus with an increased chance of cardiovascular events (Nawrot, Perez, Kunzli, Munters, \& Nemery, 2011). Moreover, stress management and lifespan are also negatively associated (Koenig, Walker, Romeo, \& Lupien, 2011). For example, Keller et al. (Keller et al., 2012) demonstrated that stress-reactive individuals present an increased risk of $43 \%$ to premature death than non-reactive individuals.

On the other hand, it is suggested that high levels of physical fitness might be associated with a lower chance of cardiovascular events (Blair, Cheng, \& Holder, 2001; Blair et al., 1996). In addition, it has been shown that even a single exercise session performed before stress situations may be helpful to attenuate hyper-reactivity to stress. MacDonald et al. (MacDonald, Hogben, Tarnopolsky, \& MacDougall, 2001), acutely submitted 8 physically active men to 30 minutes of aerobic exercise in cycle ergometer and then to simulation of several situations of activities of daily living and reported a lowered blood pressure reactivity in relation to the control session without exercise. Similarly, Ribeiro et al. (Ribeiro et al., 2011) submitted 12 university professors to 30 minutes of aerobic cycle ergometer exercise and demonstrated a lower BP response in subsequent teaching hours compared to the control session. These investigations were done acutely, observing he effects of a single exercise session on blood pressure responses to daily living situations, and little is known regarding the effects of physical fitness level on reactivity to stress.

Traditionally, aerobic fitness has been the most commonly used parameter to predict the risks of cardiovascular events and mortality (Blair et al., 1996). Recently, Oliveira-Silva et al. (Oliveira-Silva et al., 2016) evidenced that cardiovascular reactivity to commercial flights, as measured through HRV markers of sympathetic activity, were lowered in the participants with a higher fitness level and leaner body composition. However, additional investigations looking for the effects of strength on stress reactivity are needed. Among the methods applied to evaluate the cardiovascular reactivity to stress, the cold pressor test (CPT), which is considered a sympathetic-excitatory maneuver, is a simple, non-invasive and validated test (Lafleche, Pannier, Laloux, \& Safar, 1998). This protocol has been widely used to predict cardiovascular diseases (Kasagi, Akahoshi, \& Shimaoka, 1995; Menkes et al., 1989; Nisell, Hjemdahl, Linde, \& Lunell, 1985) by the analysis of physiological parameters such as, blood pressure (Moriyama \& Ifuku, 2010; Sinha \& Dubey, 2016), heart rate (Okada et al., 2016) or adrenergic hormones (Nami et al., 1981).

Mostly of the hemodynamic and endocrine responses to static stress protocols may be due to increased sympathetic activation and parasympathetic withdrawn (Salman, 2016). It has been demonstrated that individuals with decreased heart rate variability (HRV) at rest, a reflection of increased sympathetic tone, have greater chances of cardiovascular events (Dekker et al., 2000; Sajadieh, Rasmussen, Hein, \& Hansen, 2003). Nevertheless, HRV responses to CPT have been poorly investigated. Mourot et al. (Mourot, Bouhaddi, \& Regnard, 2009) reported that individuals presenting a higher reactivity to stress during the 
CPT had an increased and sustained sympathetic activation, whereas the non-reactive ones had a decrease in HR after the initial increase, possibly due to vagal co-activation.

The relationship of the muscle strength levels (as a measure of physical fitness level) to cardiovascular reactivity to CPT was not investigated yet. The handgrip test has gained prominence as a tool to measure strength, since it allows for the evaluation of large groups, with low time expenditure. Not to mention that among the direct tests to measure physical qualities related to health, it is one of the most practical and lower cost tests (Newman et al., 2006; Rantanen et al., 2003; Sasaki, Kasagi, Yamada, \& Fujita, 2007). Thus, the present study aimed to investigate the autonomic responses to cold pressor test (CPT) in individual with different levels of handgrip strength. It was hypothesized that individuals with higher muscle strength would have lowered autonomic and cardiovascular reactivity to stress.

\section{Materials And Methods}

The study was characterized as cross-sectional research which, according to (Bastos \& Duquia, 2007), is an observational method.

After approval by the local ethics committee (protocol: 42085515.0.0000.0029), 57 male subjects, aged between 18 to 30 years participated in the study. Inclusion criteria were: a) free of any bone, muscle, or joint injury or neurological disorder that would preclude performing the experimental sessions; b) no use of any pharmacological substance that could influence autonomic or cardiovasculares systems, and d) only healthy individuals who signed the informed consent term would be included in this study. This experiment was conducted in accordance to the Declaration of Helsinki (466/2012).

\section{Sample and General Procedures}

Initially, participants had their body composition assessed. To determine body fat percentage, we performed skinfold measurement according to the seven folds protocol and calculation as previously described (Jackson \& Pollock, 1978; Jackson, Pollock, \& Ward, 1980; Siri, 1961). To assess physical fitness status we tested isometric strength using a dynamometer handgrip (Jamar ${ }^{\circledR}$, IL, USA). This procedure was conducted as follows: the subjects remained seated with their shoulder adducted and neutrally rotated, elbow flexed at $90^{\circ}$, forearm in neutral position, and wrist between $0^{\circ}$ and $30^{\circ}$ dorsiflexion and between $0^{\circ}$ and $15^{\circ}$ ulnar deviation, collected three times with one-minute interval. The best of the three attempts was used for the strength measure (Mathiowetz et al., 1985). The relative handgrip strength (RHS) was calculated based on body mass and then divided in tertiles according to their level of RHS as Low (LS), Medium (MS) and High (HS) strength.

After this initial assessment and general procedures, volunteers were divided in tertiles by their level of RHS. Each group had 19 subjects for final analyses. Characteristics of the sample are displayed on Table 1 . The statistical power conferred to the main analyses (three groups; four measures; HRV) were $90 \%(1-\beta=0.9)$ considering an effect size of $f=0.2$ and $\alpha=$ 0.05 . 
Table 1. Characteristics of the sample. Data expressed in mean and ( \pm ) standard deviation.

\begin{tabular}{lccc}
\hline & $\begin{array}{c}\text { LS } \\
(\mathrm{n}=19)\end{array}$ & $\begin{array}{c}\text { MS } \\
(\mathrm{n}=19)\end{array}$ & $\begin{array}{c}\text { HS } \\
(\mathrm{n}=19)\end{array}$ \\
\hline Age $(\mathrm{y})$ & $26.6 \pm 3.9$ & $25.3 \pm 3.6$ & $27.0 \pm 5.0$ \\
Body mass $(\mathrm{kg})$ & $87.0 \pm 11.9 *$ & $76.8 \pm 7.5$ & $71.7 \pm 8.9$ \\
Height $(\mathrm{cm})$ & $175.8 \pm 6.4$ & $173.8 \pm 6.9$ & $174.4 \pm 7.7$ \\
BMI $\left(\mathrm{kg} \cdot \mathrm{m}^{-2}\right)$ & $28.1 \pm 3.9 *$ & $25.4 \pm 2.8$ & $23.6 \pm 2.8$ \\
Body fat (\%) & $21.4 \pm 4.4 *$ & $17.1 \pm 5.1$ & $14.5 \pm 5.0$ \\
Waist-to-height ratio & $0.51 \pm 0.05 *$ & $0.48 \pm 0.04$ & $0.46 \pm 0.03$ \\
Waist-to-hip ratio & $0.88 \pm 0.06$ & $0.85 \pm 0.04$ & $0.85 \pm 0.04$ \\
Handgrip strength (kgf) & $41.3 \pm 6.3$ & $44.8 \pm 4.0$ & $51.8 \pm 6.4 *$ \\
Handgrip strength & $47.6 \pm 5.1 *$ & $58.4 \pm 2.7 *$ & $72.8 \pm 9.2 *$ \\
(kgf/kg*100) & & & \\
\hline
\end{tabular}

LS: low relative strength; MS: middle relative strength; HS: high relative strength; BMI: body mass index; *: significant difference from the other two groups. Source: Authors.

Volunteers were advised to avoid coffee, alcohol and maintain their daily life activities in the 48 hours prior to analysis. A preliminary verbal instruction was conducted with each individual about the procedure.

For the CPT the volunteers remained seated at rest for 15 minutes and immerged the right hand in cold water $\left(4-5^{\circ} \mathrm{C}\right)$ for two minutes, as previously suggested (Hines \& Brown, 1936). Blood pressure (BP) measurements were taken at rest, during the $1^{\text {st }}$ and $2^{\text {nd }}$ minute of CPT, and during recovery $\left(1^{\text {st }}, 3^{\text {rd }}\right.$ and $5^{\text {th }}$ minutes) using an automated sphygmomanometer (Microlife BP3AC1-1PC).

\section{Heart Rate Variability Analysis}

HRV was continuously recorded during the entire protocol using Cardiofrequemeter (Polar ${ }^{\circledR}$ RS800CX). All measurements were divided in four intervals for further analyses using Kubios HRV Version 2.1 software package (Biosignal Analysis and Medical Imaging Group, Finland): (1) last 10 minutes of the 15 minutes at rest; (2) first minute of CPT (with submerged hand in cold water); (3) second minute with submerged hand in cold water during CPT; (4) the first three minutes of recovery from CPT; and (5) final three recovery minutes. The participants' spectral HRV auto-regression was expressed in terms of three components in normalized units (n.u.): low frequency (LF) power, high frequency (HF) power, and the natural $\log$ of root-square-mean difference of successive normal RR intervals (LnRMSSD). Figure 1 presents low- and high-strength subjects HRV individual analysis at rest, CPT and recovery. Figure 1 shows the behavior of HRVduring the test. A reduction in HRV is observed during CPT. 
Figure 1. Individual analysis of the heart rate variability of an individual of low relative strength (Fig. 1-A) and a subject of high relative strength (Fig. 1-B) at rest, during the two-minute CPT and recovery.

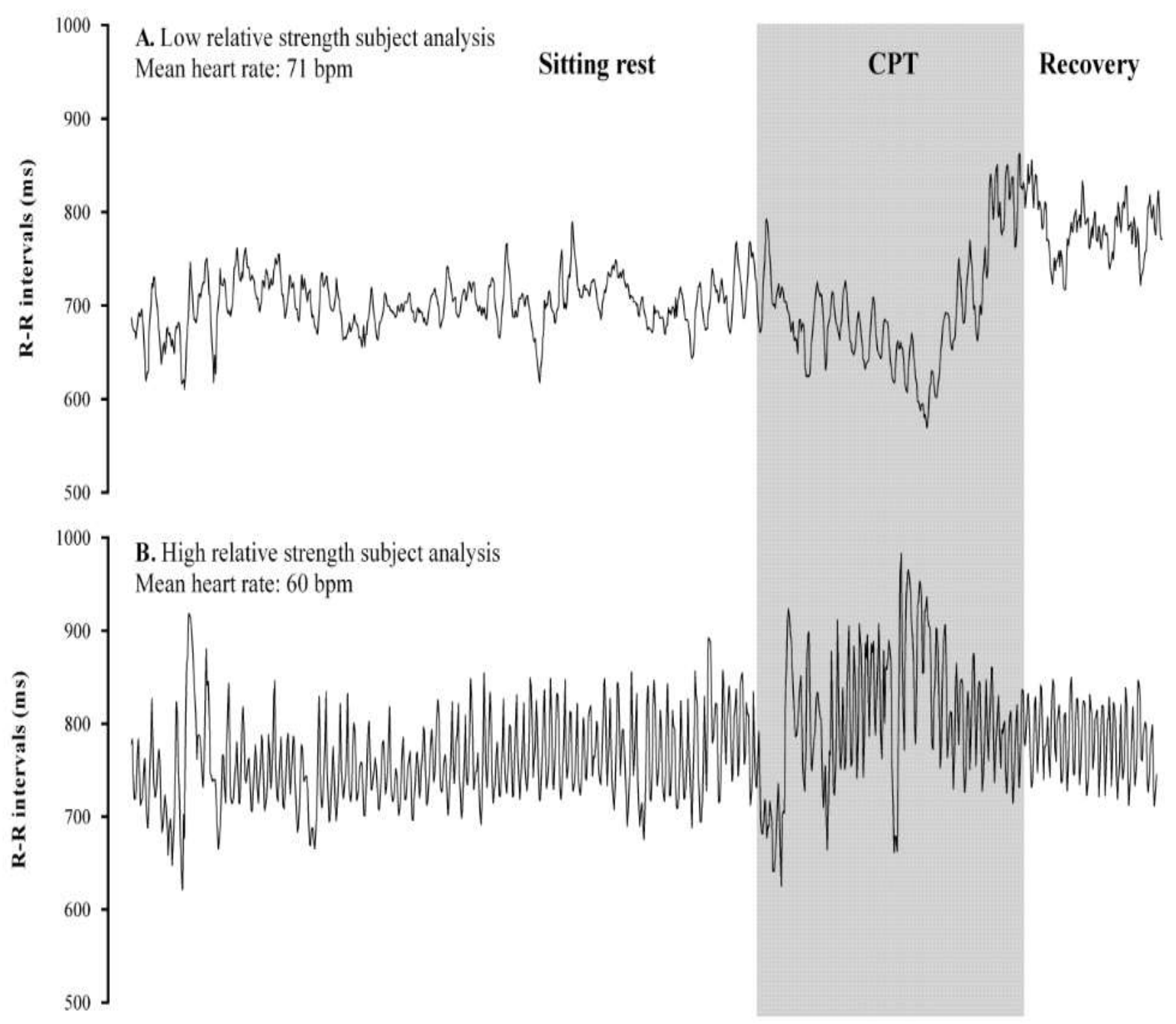

Source: Authors.

\section{Statistical Analysis}

After assessing normality and homogeneity of data through the Shapiro-Wilk and Levene's test respectively, data were presented as means and standard deviation $( \pm)$. In order to compare the characteristics of the groups, an analysis of variance (One Way ANOVA) was applied with Tukey's post hoc. ANCOVA for repeated measurements with interactions within- and between-factors were used to compare the different moments of the different groups. Body mass index (BMI) was added as a covariant due to the statistical difference between groups. When any of the dependent variables did not show sphericity in the Mauchly's test, the epsilon of Greenhouse-Geisser was used to analyze the $F$ statistic. The significance level was set at $5 \%(\mathrm{p}<0.05)$. All the procedures were carried out using the Statistical Package for the Social Sciences (SPSS 21.0) and $\mathrm{G}^{*}$ Power (version 3.1.9.2). 


\section{Results}

The groups stratified in tertiles by using the relative handgrip strength (RHS), and the LS group presented higher values of body mass, BMI, body fat and waist-to height ratio for the low-strength group in comparison to middle-strength (MS) and high-strength (HS). Elevated values of absolute handgrip strength (AHS) were identified for the HS. Regarding RHS values, the three groups differed among each other (See Table 1).

Absolute analysis demonstrated that all three groups had similar BP variation, with the values of systolic blood pressure (SBP) increasing during CPT and diminishing during recovery until the third minute. No between-group differences were identified for SBP. Diastolic blood pressure (DBP) also elevated during CPT returning to rest values at the first recovery minute. LS group showed higher levels of DBP than MS at the second CPT minute. As expected, mean arterial pressure (MAP) demonstrated higher values during CPT and inferior at the third recovery minute, which was also lower than rest values for the LS group (See Table 2).

Table 2. Absolute values of systolic and diastolic blood pressure during the cold pressor test. Data expressed in mean and $( \pm)$ standard deviation.

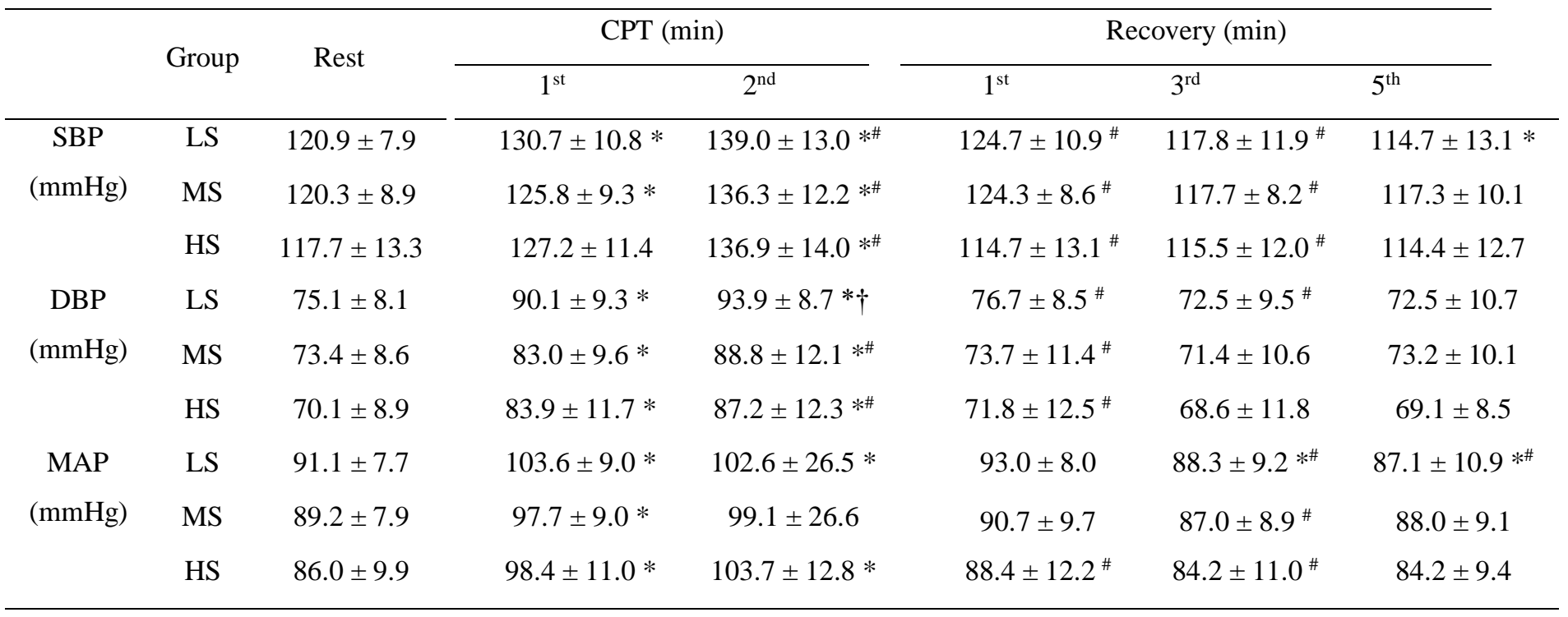

CPT: cold pressor test; SBP: systolic blood pressure; DBP: diastolic blood pressure; MAP: mean arterial pressure; LS: low strength group $(n=19)$; MS: middle strength group ( $n=19)$; HS: high strength group $(n=19)$; *: different from rest values; \#: different from previous moment; $\dagger$ : different from MS group. Source: Authors.

HRV absolute analyses demonstrated a discrepant behavior between the groups. At the first CPT minute LS group showed a substantial increase in LF activity and a diminished HF. LS also presented higher and lower values of LF and HF, respectively, than MS group at the first CPT minute. Further, the recovery analysis for MS group evidenced an elevated HF activity and lowered LF activity during the first three recovery minutes in comparison to rest values. The HS group showed elevated values of LnRMSSD during recovery, which represents an increased vagal activity. (Table 3). 
Table 3. Absolute values of heart rate variability during the cold pressor test. Data expressed in mean and ( \pm ) standard deviation.

\begin{tabular}{llccccc}
\hline \multirow{2}{*}{ Group } & Rest & \multicolumn{2}{c}{ CPT } & \multicolumn{2}{c}{ Recovery (min) } \\
\cline { 5 - 7 } & & & $1^{\text {st }}$ & $2^{\text {nd }}$ & $3^{\text {rd }}$ & $3^{\text {rd }}-5^{\text {th }}$ \\
\hline LnRMSSD & LS & $1.56 \pm 0.33$ & $1.52 \pm 0.33$ & $1.56 \pm 0.35$ & $1.64 \pm 0.29$ & $1.55 \pm 0.32^{\#}$ \\
& MS & $1.57 \pm 0.21$ & $1.65 \pm 0.25$ & $1.68 \pm 0.27 *$ & $1.72 \pm 0.27 *$ & $1.61 \pm 0.24^{\#}$ \\
& HS & $1.55 \pm 0.24$ & $1.60 \pm 0.16$ & $1.59 \pm 0.22$ & $1.73 \pm 0.20 * *^{*} \dagger$ & $1.64 \pm 0.21 *^{*} \dagger$ \\
LF (n.u.) & LS & $66.2 \pm 18.8 \dagger$ & $76.9 \pm 12.0 * *$ & $69.2 \pm 15.3$ & $67.8 \pm 9.3 \dagger$ & $68.3 \pm 10.3 \dagger$ \\
& MS & $65.9 \pm 15.4$ & $60.5 \pm 16.5$ & $63.9 \pm 16.2$ & $57.8 \pm 18.6 *$ & $68.8 \pm 12.6 \dagger^{\#}$ \\
& HS (n.u.) & $71.8 \pm 15.6$ & $69.8 \pm 20.6$ & $67.9 \pm 25.8$ & $65.2 \pm 19.7$ & $67.5 \pm 15.6$ \\
& LS & $33.8 \pm 18.7 \dagger$ & $23.1 \pm 12.0 * *$ & $30.8 \pm 15.3$ & $32.1 \pm 9.3 \dagger$ & $31.7 \pm 10.3$ \\
& MS & $34.1 \pm 15.4$ & $39.4 \pm 16.5$ & $36.0 \pm 16.2$ & $42.2 \pm 18.6 *$ & $31.1 \pm 12.6 \dagger^{\#}$ \\
& HS & $28.1 \pm 15.6$ & $30.2 \pm 20.6$ & $32.0 \pm 25.8$ & $34.8 \pm 19.7$ \# & $32.4 \pm 15.7$ \\
\hline
\end{tabular}

CPT: cold pressor test; LF: low-frequency; HF: high-frequency; LS: low relative strength (n=19); MS: middle relative strength (n=19); HS: high relative strength $(\mathrm{n}=19)$; *: different from rest ; **: different from MS group. ${ }^{\#}$ : different from previous moment; $\dagger$ : different from $1^{\text {st }}$ CPT minute. Source: Authors.

Figure 2 presents the delta analysis of autonomic balance and SBP values during CPT and recovery. At the first CPT minute LS group presented higher levels of LF and reduced levels of HF than MS and HS group. At the final CPT minute, SBP substantially increased in all three groups, but the only significant change identified was for the HS group, which has significantly increased LF/HF ratio. During recovery, the LS group presented reduced levels of LF and increased HF in the first measure ( $3^{\text {rd }}$ minute) and maintained in the final measure $\left(5^{\text {th }}\right.$ minute). MS group showed reduced LF and increased HF only in the final recovery measure. No differences were identified for the HS group. 
Figure 2. Analysis of autonomic balance.
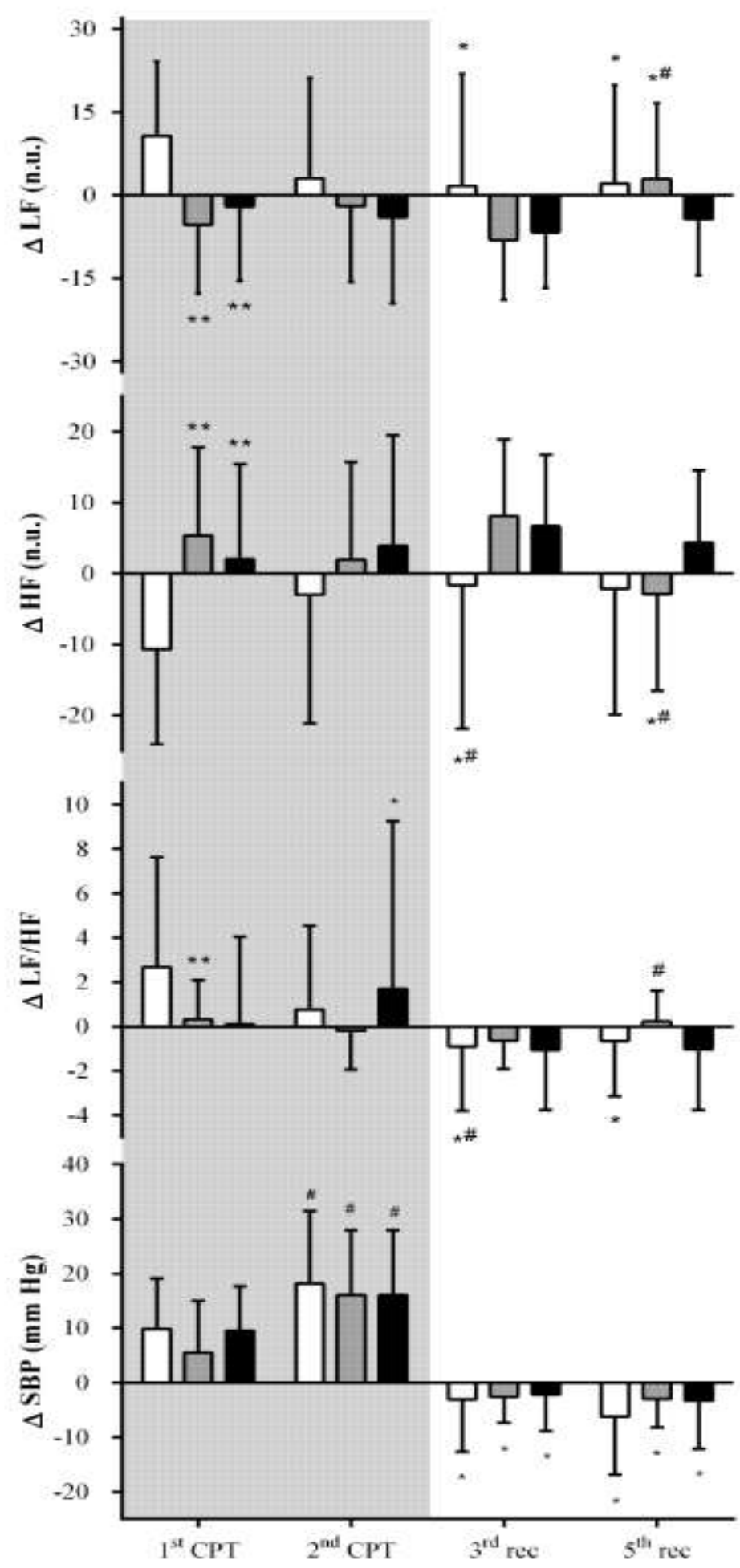

Absolute variation $(\Delta)$ of low frequency (LF), high frequency, LF / HF ratio and systolic blood pressure (PAS) during the cold pressor test $(\mathrm{CPT})$ and recovery. White bars: low relative strength; Gray bars: average relative strength; Black bars: high relative resistance; *: Different from the first minute of the CPT; \#: Different from the previous moment. **: different from the low resistance group. Source: Authors.

\section{Discussion}

The aim of this study was to investigate the autonomic and cardiovascular outcomes to CPT in young men of different levels of physical fitness, as measure though handgrip relative strength (HRS). The main finding was that, although BP seems 
to have a similar variation in all the three groups, HRV analyses demonstrated that individuals with lower HRS presented a higher autonomic reactivity to CPT.

The first physiological trigger by an static stress (i.e. CPT) is a orchestration by a complex supramedullary network of neurons in the limbic system, amygdala and hypothalamus sending synaptic projections to the central autonomic centers, increasing sympathetic activity (Fontes, Xavier, de Menezes, \& Dimicco, 2011; Fontes et al., 2014). This sympathetic outflow, preparing the body to a "fight or flight" situation (Dampney et al., 2002; Salman, 2016), is responsible for increasing heart rate, peripheral vascular resistance, and adrenal activity (Salman, 2016; Tank \& Lee Wong, 2015) in parallel to a decreased HRV (Mourot et al., 2009).

If there is no need to maintain or increase the cardiac output after the initial stress (i.e. static protocol) a quick vagal reactivity is promoted via baroreflex activation (DiMicco, Gale, Hamilton, \& Gillis, 1979). In other words, the elevated peripheral vascular resistance responsible for increasing BP, is also accountable to trigger baroflexes and induces a vagal outflow in an attempt to return the system to homeostasis (Salman, 2016).

In present study the LS group had a significant increase in sympathetic activity (LF) and consequently, a reduction in vagal activity (HF) in the first CPT minute. However, right in the second CPT minute a substantial vagal outflow followed by a decreased LF activity was observed, maintaining these levels during recovery. On the other hand, the MS group had a different response, with a slightly and non-significant increase in HF activity and decrease in LF in the first CPT minute, which may be a result of a quicker vagal response in this one minute interval, as previously hypothesized (Glenn \& Ditto, 2003; Sendowski, Savourey, Besnard, \& Bittel, 1997). Indeed, it has been demonstrated that individuals with a better fitness status may have an elevated baroreflex sensitivity (Molgaard, Hermansen, \& Bjerregaard, 1994; Taylor \& Eckberg, 1996), which can be reflected in the present results with the increased BP but reduced LF activity for the MS group.

For the HS group, although it is observed a similar BP response as the other groups, the autonomic activity did not show any significant change during CPT, but an increased vagal activity during recovery (elevated LnRMSSD). These results may be a reflection of more sensible sympathetic receptors, in which a smaller sympathetic activity (i.e. decreased LF) may induce similar cardiovascular outcomes (i.e. increased SBP). It has been demonstrated that physical activity is positively associated with vagal activity and baroreflex sensitivity (Molgaard et al., 1994; Taylor \& Eckberg, 1996).

During a physiological stress protocol, such as physical exercise, a reduction in vagal activity is the initial response, followed by a catecholaminergic response to sustain the cardiometabolic demand (Guimaraes \& Moura, 2001; Tank \& Lee Wong, 2015). Some studies even reported a decreased sympathetic activity during a rectangular exercising protocol in athletes (Kamath, Fallen, \& McKelvie, 1991; Shin, Minamitani, Onishi, Yamazaki, \& Lee, 1995a, 1995b), which corroborates with the results of the present study for MS and HS subjects.

Additional studies investigated the autonomic response to exercise stress protocols comparing by the level of physical fitness and demonstrated that more trained individuals have an increased vagal activity during the test (elevated HF) than less trained individuals (Aubert et al., 1999; Dixon, Kamath, McCartney, \& Fallen, 1992). Another one reported that, besides the decreased HF, also an increased LF (Furlan et al., 1993), which may represent the capacity of trained individuals to have a better autonomic control to increase the cardiometabolic offer via sympathetic outflow when it needs.

The autonomic responses to CPT have already been investigated in healthy subjects (Mourot et al., 2009), obese adults (Grewal, Sekhon, Walia, \& Gambhir, 2015), as well as in different ethnic groups (Okada et al., 2016) and the effect of gender (Fu, Witkowski, Okazaki, \& Levine, 2005). However, to the best of our knowledge, this is the first study that compared by physical fitness (relative handgrip strength) on physiological responses to CPT.

Furthermore, some evidence suggests that body composition alone might predict HRV at rest or during recovery from stress induced situations (Esco \& Williford, 2013; Esco, Williford, \& Olson, 2011; Oliveira-Silva et al., 2016). Esco et al. 
(Esco et al., 2011) demonstrated that between some selected body composition parameters and $\mathrm{VO}_{2}$ max, total skinfold thickness was the strongest predictor of rest HRV and autonomic recovery after exercise. Furthermore, Oliveira-Silva et al. (Oliveira-Silva et al., 2016) reported that body composition and physical fitness are positively associated with autonomic control during stress-induced circumstances (domestic flights). Nevertheless, the subjects on the present study have showed similar body composition, and the only variable that shown statistical difference (BMI) was included as a covariant in the comparison analyses to minimize bias.

As a practical application, the present result suggests that handgrip strength can be used as an alternative method to predict possible autonomic and cardiovascular changes reactivity to stress situations. This outcome may be useful in clinical practice to avoid submitting hyper-reactive patients to unnecessary stress procedures by only assessing the handgrip strength.

\section{Conclusion}

In conclusion, individuals with lower HRS have similar BP response to CPT than middle and high HRS groups, but with higher sympathetic activation. We further suggest that future studies would evaluate the possible underlying mechanisms, such as the adrenergic and baroreflex responses, in individuals of different fitness level, including athletes. Investigation of the effects of detraining-retraining on this protective cardiovascular effect of physical fitness level would also be analyzed.

\section{Acknowledgments}

We are grateful to the Research Support Fund of the Federal District - FAP-DF for granting a Master's scholarship.

\section{References}

Aubert, A., Ramaekers, D., Collier, B., Beckers, F., Van de Werf, F., \& Ector, H. (1999). Comparison of the effect of different types of exercise on short-term heart rate variability. Med Biol Eng Comput, 37, 568-569.

Bastos, J. L. D., \& Duquia, R. P. (2007). Um dos delineamentos mais empregados em epidemiologia: estudo transversal. Scientia Medica, 17(4), 229-232.

Blair, S. N., Cheng, Y., \& Holder, J. S. (2001). Is physical activity or physical fitness more important in defining health benefits? Medicine and science in sports and exercise, 33(6), 379-399.

Blair, S. N., Kampert, J. B., Kohl, H. W., Barlow, C. E., Macera, C. A., Paffenbarger, R. S., \& Gibbons, L. W. (1996). Influe nces of cardiorespiratory fitness and other precursors on cardiovascular disease and all-cause mortality in men and women. JAMA, 276(3), 205-210\%@ 0098-7484.

Dampney, R. A., Coleman, M. J., Fontes, M. A., Hirooka, Y., Horiuchi, J., Li, Y. W., \& Tagawa, T. (2002). Central mechanisms underlying short- and longterm regulation of the cardiovascular system. Clin Exp Pharmacol Physiol, 29(4), 261-268.

Dekker, J. M., Crow, R. S., Folsom, A. R., Hannan, P. J., Liao, D., Swenne, C. A., \& Schouten, E. G. (2000). Low heart rate variability in a 2-minute rhythm strip predicts risk of coronary heart disease and mortality from several causes: the ARIC Study. Atherosclerosis Risk In Communities. Circulation, 102(11), $1239-1244$

DiMicco, J. A., Gale, K., Hamilton, B., \& Gillis, R. A. (1979). GABA receptor control of parasympathetic outflow to heart: characterization and brainstem localization. Science, 204(4397), 1106-1109.

Dixon, E. M., Kamath, M. V., McCartney, N., \& Fallen, E. L. (1992). Neural regulation of heart rate variability in endurance athletes and sedentary controls. Cardiovasc Res, 26(7), 713-719.

Esco, M. R., \& Williford, H. N. (2013). Relationship between post-exercise heart rate variability and skinfold thickness. SpringerPlus, $2(1)$, 1.

Esco, M. R., Williford, H. N., \& Olson, M. S. (2011). Skinfold thickness is related to cardiovascular autonomic control as assessed by heart rate variability and heart rate recovery. The Journal of Strength \& Conditioning Research, 25(8), 2304-2310.

Fontes, M. A., Xavier, C. H., de Menezes, R. C., \& Dimicco, J. A. (2011). The dorsomedial hypothalamus and the central pathways involved in the cardiovascular response to emotional stress. Neuroscience, 184, 64-74. doi:10.1016/j.neuroscience.2011.03.018

Fontes, M. A., Xavier, C. H., Marins, F. R., Limborco-Filho, M., Vaz, G. C., Muller-Ribeiro, F. C., \& Nalivaiko, E. (2014). Emotional stress and sympathetic activity: contribution of dorsomedial hypothalamus to cardiac arrhythmias. Brain Res, 1554, 49-58. doi:10.1016/j.brainres.2014.01.043

Fu, Q., Witkowski, S., Okazaki, K., \& Levine, B. D. (2005). Effects of gender and hypovolemia on sympathetic neural responses to orthost atic stress. Am J Physiol Regul Integr Comp Physiol, 289(1), R109-116. doi:10.1152/ajpregu.00013.2005 
Furlan, R., Piazza, S., Dell'Orto, S., Gentile, E., Cerutti, S., Pagani, M., \& Malliani, A. (1993). Early and late effects of exercise and athletic training on neural mechanisms controlling heart rate. Cardiovasc Res, 27(3), 482-488.

Glenn, D., \& Ditto, B. (2003). Vagal tone biofeedback: Respiratory and non-respiratory mediated modulations of vagal tone challenged by cold pressor test. McGill Journal of Medicine, 7(2), 143-152.

Grewal, S., Sekhon, T. S., Walia, L., \& Gambhir, R. S. (2015). Cardiovascular response to acute cold stress in non-obese and obese healthy adults. Ethiop J Health Sci, 25(1), 47-52.

Guimaraes, S., \& Moura, D. (2001). Vascular adrenoceptors: an update. Pharmacol Rev, 53(2), 319-356.

Hines, E. A., \& Brown, G. E. (1936). The cold pressor test for measuring the reactibility of the blood pressure: data concerning 571 normal and hypertensive subjects. American heart journal, 11(1), 1-9.

Jackson, A. S., \& Pollock, M. L. (1978). Generalized equations for predicting body density of men. Br J Nutr, 40(3), 497-504.

Jackson, A. S., Pollock, M. L., \& Ward, A. (1980). Generalized equations for predicting body density of women. Med Sci Sports Exerc, 12(3), 175-181.

Kamath, M. V., Fallen, E. L., \& McKelvie, R. (1991). Effects of steady state exercise on the power spectrum of heart rate variability. Med Sci Sports Exerc, 23(4), 428-434.

Kasagi, F., Akahoshi, M., \& Shimaoka, K. (1995). Relation between cold pressor test and development of hypertension based on 28-year follow-up. Hypertension, 25(1), 71-76.

Keller, A., Litzelman, K., Wisk, L. E., Maddox, T., Cheng, E. R., Creswell, P. D., \& Witt, W. P. (2012). Does the perception that stress affects health matter? The association with health and mortality. Health Psychology, 31(5), 677.

Koenig, J. I., Walker, C. D., Romeo, R. D., \& Lupien, S. J. (2011). Effects of stress across the lifespan. Stress, 14(5), 475-480. doi:10.3109/10253890.2011.604879

Lafleche, A., Pannier, B., Laloux, B., \& Safar, M. (1998). Arterial response during cold pressor test in borderline hypertension. American Journal of Physiology-Heart and Circulatory Physiology, 275(2), H409-H415.

MacDonald, J., Hogben, C., Tarnopolsky, M., \& MacDougall, J. (2001). Post exercise hypotension is sustained during subsequent bouts of mild exercise and simulated activities of daily living. J Hum Hypertens, 15(8), 567-571.

Mathiowetz, V., Kashman, N., Volland, G., Weber, K., Dowe, M., \& Rogers, S. (1985). Grip and pinch strength: normative data for adults. Arch Phys Med Rehabil, 66(2), 69-74.

Menkes, M. S., Matthews, K. A., Krantz, D. S., Lundberg, U., Mead, L. A., Qaqish, B., . . Pearson, T. A. (1989). Cardiovascular reactivity to the cold pressor test as a predictor of hypertension. Hypertension, 14(5), 524-530.

Molgaard, H., Hermansen, K., \& Bjerregaard, P. (1994). Spectral components of short-term RR interval variability in healthy subjects and effects of risk factors. Eur Heart J, 15(9), 1174-1183.

Moriyama, K., \& Ifuku, H. (2010). Increased cardiovascular reactivity to the cold pressor test is not associated with increased reactivity to isometric handgrip exercise. Eur J Appl Physiol, 108(4), 837-843. doi:10.1007/s00421-009-1299-8

Mourot, L., Bouhaddi, M., \& Regnard, J. (2009). Effects of the cold pressor test on cardiac autonomic control in normal subjects. Physiol Res, 58(1), 83-91.

Nami, R., Pizzuti, M., D'Ascenzo, G., Bianchini, C., Bartalini, P., \& Gennari, C. (1981). Blood levels of catecholamines, cyclic AMP and cyclic GMP in endogenous adrenergic stimulation (cold pressor test and hand-grip) in humans. Boll Soc Ital Cardiol, 26(5), 457-463.

Nawrot, T. S., Perez, L., Kunzli, N., Munters, E., \& Nemery, B. (2011). Public health importance of triggers of myocardial infarction: a comparative risk assessment. Lancet, 377(9767), 732-740. doi:10.1016/S0140-6736(10)62296-9

Newman, A. B., Kupelian, V., Visser, M., Simonsick, E. M., Goodpaster, B. H., Kritchevsky, S. B., \& Harris, T. B. (2006). Strength, but not muscle mass, is associated with mortality in the health, aging and body composition study cohort. J Gerontol A Biol Sci Med Sci, 61(1), 72-77.

Nisell, H., Hjemdahl, P., Linde, B., \& Lunell, N. O. (1985). Sympatho-adrenal and cardiovascular reactivity in pregnancy-induced hypertension. I. Responses to isometric exercise and a cold pressor test. Br J Obstet Gynaecol, 92(7), 722-731.

Okada, Y., Jarvis, S. S., Best, S. A., Edwards, J. G., Hendrix, J. M., Adams-Huet, B., \& Fu, Q. (2016). Sympathetic Neural and Hemodynamic Responses During Cold Pressor Test in Elderly Blacks and Whites. Hypertension, 67(5), 951-958. doi:10.1161/HYPERTENSIONAHA.115.06700

Oliveira-Silva, I., Leicht, A., de Moraes, M., Simões, H. G., Del Rosso, S., Córdova, C., \& Boullosa, D. (2016). Heart rate and cardiovascular responses to commercial flights: relationships with physical fitness. Front Physiol, 7(648). doi:10.3389/fphys.2016.00648

Rantanen, T., Volpato, S., Ferrucci, L., Heikkinen, E., Fried, L. P., \& Guralnik, J. M. (2003). Handgrip strength and cause-specific and total mortality in older disabled women: exploring the mechanism. J Am Geriatr Soc, 51(5), 636-641.

Ribeiro, F., Campbell, C., Mendes, G., Arsa, G., Moreira, S. R., da Silva, F. M., \& Simões, H. G. (2011). Exercise lowers blood pressure in university professors during subsequent teaching and sleeping hours. Int J Gen Med, 4, 711-716.

Sajadieh, A., Rasmussen, V., Hein, H. O., \& Hansen, J. F. (2003). Familial predisposition to premature heart attack and reduced heart rate variability. Am J Cardiol, 92(2), 234-236. 
Research, Society and Development, v. 10, n. 6, e16510615593, 2021

(CC BY 4.0) | ISSN 2525-3409 | DOI: http://dx.doi.org/10.33448/rsd-v10i6.15593

Salman, I. M. (2016). Major Autonomic Neuroregulatory Pathways Underlying Short- and Long-Term Control of Cardiovascular Function. Curr Hypertens Rep, 18(3), 18. doi:10.1007/s11906-016-0625-x

Sasaki, H., Kasagi, F., Yamada, M., \& Fujita, S. (2007). Grip strength predicts cause-specific mortality in middle-aged and elderly persons. Am J Med, 120(4), 337-342. doi:10.1016/j.amjmed.2006.04.018

Sendowski, I., Savourey, G., Besnard, Y., \& Bittel, J. (1997). Cold induced vasodilatation and cardiovascular responses in humans during cold water immersion of various upper limb areas. Eur J Appl Physiol Occup Physiol, 75(6), 471-477. doi:10.1007/s004210050191

Shin, K., Minamitani, H., Onishi, S., Yamazaki, H., \& Lee, M. (1995a). The power spectral analysis of heart rate variability in athletes during dynamic exercise--Part I. Clin Cardiol, 18(10), 583-586.

Shin, K., Minamitani, H., Onishi, S., Yamazaki, H., \& Lee, M. (1995b). The power spectral analysis of heart rate variability in athletes during dynamic exercise--Part II. Clin Cardiol, 18(11), 664-668.

Sinha, B., \& Dubey, D. K. (2016). Blood pressure variability and baroreflex sensitivity of a healthy male during cold pressor test that induced development of neurocardiogenic syncope. J Basic Clin Physiol Pharmacol. doi:10.1515/jbcpp-2015-0004

Siri, W. E. (1961). Body composition from fluid spaces and density: analysis of methods. Techniques for measuring body composition, 61 , $223-244$.

Tank, A. W., \& Lee Wong, D. (2015). Peripheral and central effects of circulating catecholamines. Compr Physiol, 5(1), 1-15. doi:10.1002/cphy.c140007

Taylor, J. A., \& Eckberg, D. L. (1996). Fundamental relations between short-term RR interval and arterial pressure oscillations in humans. Circulation, 93(8), 1527-1532. 